\title{
Corrections
}

In and before Equation (30) of the paper

\section{The rheological behaviour of suspensions of fat particles in oil interpreted} in terms of a transient-network model

by H. Kamphuis and R. J. J. Jongschaap

appeared in Colloid \& Polymer Science 263:1008-1024 (1985), the phrase

$$
\frac{n_{o}(1)}{n_{o}} \lim _{\omega \rightarrow 0} G^{\prime}(\omega)
$$

should be replaced by

$$
\frac{n_{o}(1)}{n_{o}} \lim _{\omega \rightarrow \infty} G^{\prime}(\omega)
$$

Moreover the text in Figure 4 has been omitted. The flattest curve corresponds with the "single chain". 